V.

\title{
Zur Methodologie des geschichtlichen Denkens.
} Von

\section{Carl Fries.}

Die Behandlung methodologischer Fragen wird ohne Theorie und Deduktion, besonders wenn Polemiken hineinspielen, niemals auskommen, und auch unsere vorige Betrachtung der Methodenlehre ${ }^{1}$ ) verzichtete nicht auf dieses Rüstzeug. Wo jedoch wie bei Methodenfragen für den Ausschlag alles von dem Grad ihrer Bewährung abhängen muß, genügt ein konstruktives, logisch-ableitendes Verfahren wohl kaum, wenn nicht dem empfohlenen Handwerkzeug auch Gelegenheit geboten wird, sich über die Realität der ihm beigelegten Fähigkeiten gleichsam am lebendigen Objekt, am konkreten Fall. zu erproben. Ein solcher konkreter Fall soll hier nur gesetzt und das Experiment zur Kontrolle des vorher deduktiv Beigebrachten ausgefïhrt werden, und zwar soll ein spezielles geschichtliches Problem als Prüfstein für die Qualifikation der naturwissenschaftlichen Methode auf ihre Eignung in rein geisteswissenschaftlichen Fragen hin gewählt werden. Wenn dabei die Untersuchung sich zu sehr in Einzelheiten zu verlieren scheint, so darf demgegeniiber die Wesentlichkeit exakter Durchführung des Experiments für die Probabilität des zu erweisenden Satzes betont werden.

Die älteste Geschichte Griechenlands beginnt sich infolge glücklicher Ausgrabungen immer mehr aufzuhellen, und den neuen Tatsachen folgen die neuen Lehrmeinungen der Historiker auf dem Fuß. Es herrscht aber Zwiespalt im Lager der Hellenisten; glauben die einen noch an der alten Lehre festhalten zu sollen, die griechische Kultur sei autochthon, so meinen die anderen, wie überall in der Natur sei hier Stein auf Stein, Stufe auf Stufe geschichtet worden,

1) Diese Zeitschrift Band XVI Heft 4. 
sei die Gesamteinwirkung der uralten orientalischen Kulturstaaten mit ihrer staunenerregenden Zivilisation für Hellas von entscheidendem Einfluß gewesen. Der Streit tobt seit einigen Jahren hin und her, und der Marburger Assyriologe P. Jensen hat mit seinen Thesen zur Hom,erforschung im. Lager der altgläubigen Philologen einen Sturm der Entrïstung hervorgerufen, während sein freies Wagnis im, anderen Lager mit großer Genugtuung aufgenommen wurde. Nehmen wir den Fall einmal als Schulbeispiel und stellen wir die Frage, kann vom Standpunkt entwicklungsgeschichtlicher, biologischer Betrachtung ein kulturelles Autochthonentum, der hellenischen Bildung zugestanden werden, wenn fast rings um das Ländchen die zeugungskräftigsten, reifsten Kulturen das junge Volkstum umgaben? Ist der Prozeß der Kulturmischung weniger ein gesetzmäßiger Naturvorgang als etwa die Oxydation der Metalle oder andere chemische Vorgänge?. Doch lassen wir die allgemeinen Betrachtungen, und mọgen die Tatsachen nun für sich selbst reden.

Wilamowitz beginnt seinen Überblick über die griechische Literatur mit den lapidaren Worten: „Die griechische Literatur ist die einzige unserer Kulturwelt, die sich ganz aus sich selbst entwickelt hat", denen nichts hinzuzufügen ist. Im Kydathen 40 behauptet er, die keusche Religion Homers sei durch semitischen Götzendienst geschändet worden. Ach der keusche Homer! Die fromme Helene möchte man zitieren! Die alten Ionier dachten anders! Wie schänd-

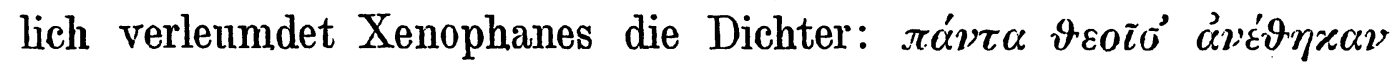

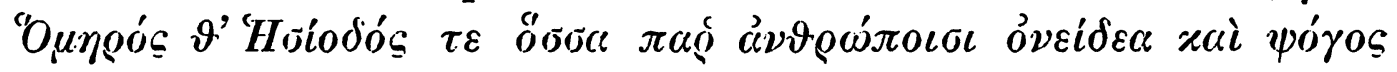

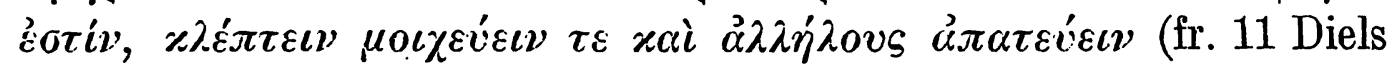
Vorsokr. vs. 12). Wieviel maßvoller und richtiger dagegen Christs Urteil in der griechischen Literaturgeschichte 413, 1: „Ich bin ein Fremdling in der Assyriologie, aber der Einsicht in offenbare Wahrheiten darf sich niemand verschließen" usw. Während die klassische Philologie sich nun fortgesetzt ablehnend verhielt, begann die orientalistische Forschung ihrerseits Eroberungszüge zu unternehmen, gleichzeitig regten sich Anthropologie, Ethnologie und Sprachvergleichung, so daß die Frage nach ältesten Völkerzusammenhängen immer dringlicher wurde. Man ging von Fall zu Fall, jeder blickte von seinem begrenzten Studiengebiet, soweit das Auge über die Grenze reichen wollte. Vernachlässigt aber blieb die Erwägung, daß hier naturwissenschaftliche 
Mcthode anzuwenden sei, daß die Völkerorganismen wie Gruppen des Naturreichs verglichen, kn- und subordiniert werden, und vor allem in einen großen iibergeordneten Zusammenhang eingereiht werden müßten. Gewiß wurde der Gedanke wohl gehegt und wohl auch ausgesprochen, zu der Herrschaft aber, die ihm gebührt, ist er nicht gelangt. Unbedingt gebuihrt ihm die Suprematie - unbedingt muß, wie in den übrigen Wissenschaften, auch hier das Bewußtsein von der Evolution durchdringen, müssen die Methoden der entwicklungsgeschichtlichen, biologischen Forschung auch für den Werdegang der Völker und ihrer Gruppierungen Platz greifen: In hundert und tausend Experimenten hat das Verfahren der exakten Forschung sich bewährt und der staunenden Welt ein beispielloses Staunen abgerungen; unerhört und durchweg umwälzend in jeder Beziehung waren die Errungenschaften dieser Wissenschaften; sie haben unserem ganzen Leben, unserem ganzen Denken und Vorstellen, unserer gesamten Philosophie und Kultur ihren ureigenen Stempel aufgedrückt, keine Seite des geistigen Lebens blieb von ihr unbeeinflußt; die Wissenschaften haben ihr ihre Methoden abgelauscht und sich nicht zu ihrem Schaden danach gerichtet. Màn wird nicht für die klassischen Philologen eine so extreme Ausnahmestellung beanspruchen, auch ihr Schaffen wird sich dem allgemeinen Gesetz unterwerfen, die bewährte Norm anerkennen müssen. Diese jedoch bedingt einen ausgesprochenen Sinn für die allen Einzelerscheinungen zugrunde liegende Einheit, die auch im Völkerleben nicht als die letzte Möglichkeit, sondern als die apriorische Voraussetzung gelten sollte. Es gibt doch nichts natürlicheres, als daß Völkerschaften, die gleichsam organisch neben einander und mit einander aufwachsen, nicht ohne Einfluß auf einander geblieben sein werden. Man denke nur an die Zellen und Gewebe. Wie da eine Existenz neben der anderen sich entwickelt, eine der anderen ähnlich, der anderen verwandt, der anderen verschwistert oder verschwägert, so sollte man doch auch die großen Komplexe, die so gruppenweise beieinander liegen, mit einer gewissen Selbstverständlichkeit als auf einander angewiesen und verwandt betrachten, mindestens aber die Möglichkeit gegenseitiger Beeinflussung zulassen. Statt dessen baut man eine große Völkerfamilie auf und in der Mitte als Waisenkind, ohne Verwandte, ohne fördernde Freunde, erscheint Hellas. In so dürftigem Aufzug läßt man die feinste Blüte der Völkermischung auftreten, weil man 
den älteren Schwestern den bildenden Einfluß auf die jüngere nicht gönnen mag. So entsteht ein Zerrbild auf jedes organische Werden, das die geschichtliche Erkenntnis hemmt und seinen Zweck, den Ehrensockel des Griechentums zu erhöhen, nimmermehr erreicht. Aber immer wieder muß der Bastiansche Völkergedanke herhalten, wenn man eine Übertragung nicht zugeben will. Wie energisch hat schon Lehrs auf die Kontinuität der Kultur hingewiesen (Pop. Aufs. 2 463 f.). Auch Ratzel sprach es aus, daß überall mit Entlehnungen zu rechnen sei (Anthropogeographie II, 725 ff.). Eine Urzeugung sei auch auf diesem. Gebiet nicht nachweisbar. Man wird stets auf biologische Analogien zurïckgefïhrt. Auch Schurtz in seinem. Werk (52 ff.) trat für allgemeinen. Kulturzusammenhang ein und wies gut darauf hin, daß die Menschheit im, ganzen einen entschiedenen Ideenmangel an den Tag lege, daß überall Nachahmung auftrete, neue Erfindung jedoch höchst spärlich zu finden sei (56). Sehen wir doch auf unsere erleuchtete Zeit, in der es nicht besser bestellt ist. Selten sind die neuen Gedanken, auf Nachahmung des Vorhandenen und ganz geringen Abwandlungen beruht aller Fortschritt. Das folgende Glied klemm.t sich zunächst ängstlich an das ältere, tu.t hundert Bewegungen auf dieses gestützt, ehe es einen selbständigen Schritt wagt: Wie gründlich ist jeder Fortschritt, auf welchem Gebiet es auch sei, vorbereitet. Und was den Orient betrifft, sagt der Orient uns heut nichts mebr? Man mustere unser Kunstgewerbe, unsere Kunst, und man wird z. B. ein starkes Band zwischen Japan und Paris, zwischen ostasiatischer und europäischer Maltechnik u. a. finden, wie Osborn das im letzten Band von Springers Kunstgeschichte so hübsch ausfuihrt. Wohin wäre es mit unserer stolzen Neuzeit gekommen, wenn der Orient nicht Kompaß, Pulver und Druck beigesteuert hätte. Rembrandt hatte in seinem. Atelier orientalische Muster, und daß das Mittelalter auf den Osten blickte, wird hoffentlich bald Gemeingut der Wissenschaft sein. Von modernen Versuchen, die Kultur aus der Gegend des Nordpols herzuleiten, wollen wir lieber schweigen. Von komischen Episoden ist keine Wissenschaft frei. Für den großen Zusammenhang kämpft seit langem verdienstvoll Otto Gruppe (Griech. Rel. u. Myth. 719 u. a.). Er sagte, die Vererbungstheorie könne man für die mythologischen Zusammenhänge der Indogermanen nicht heranziehen, aber es sei möglich, „daß auch nach ihrer Tremnung Inder, Griechen und Germanen zu denselben Religionsformen ge- 
langen konnten, indom sie sich dieselben von außen her aneigneten" (Kulte u. Mythen I, 151). Er behauptet, die Völker seien in ältester Zeit religionslos gewesen und erst von einem Kulturzentrum aus sei ihnen Mythos und Religion iiberliefert worden. Dieser Standpunkt entspricht durchaus der Biologie. Der der Tierwelt entsprossene Mensch ist natürlich zuerst religionslos in höherem Sinn, um alles Mystische und Philosophische zunächst einmal auszuschalten. Im Laufe sciner Entwicklung gelangt er zur Erleuchtung und höchsten Weltanschauung. Von einem Punkt verbreitet sich jedes Licht dann in den Wellenformen der Kulturwanderung über die Erde. Man kann diese Konsequenz in Gruppes Adaptationismus nur bewundern, und wenn man ihn auch z. T. tendenziös angegriffen hat, so ist die Wissenschaft seines Verdienstes doch längst inne geworden. So sagt z. B. W. Golther in der Germanischen Mythologie, daß die Annahme von einer Entlehnung gerade auf religiösem Gebiet ungemein viel für sich habe (36). Die Völker waren auch nach seiner Ansicht in ältester Zeit nicht so getrennt, wie man ge wöhnlich annimmt. Biologisch richtiger muß es heißen: Sie hatten sich von einander getrennt, geteilt wie Protoplasmen und trugen die Signatur innerer Verwandtschaft, so lange sie existierten, an sich. Wie die Kulturpflanzen und Haustiere nach Hehn, wanderten die Ideen von einer Zone über die Erde, wie das schwerfällige Mammut oder Nashorn bis zum äußersten Norden hinaufzogen. Hugo Winckler hat sich einmal sehr treffend hierüber ausgesprochen. Da die indogermanischen und semitischen Sprachen nicht mit einander ,verwandt" waren, sagt er in der Kritik ïber Bolls Sphära (Krit. Schr. III, 75), so konnte auch keine weitere Beziehung zwischen den Völkergruppen bestanden haben. Denn alles Geistesleben hatten sie aus sich entwickelt, alles war überall auf der Erde immer wieder von neuem herausgebildet worden. Die alten Völker hatten keinen Verkehr mit einander, da Schienen und Dampfer ihnen fremd waren. Die Ethnologie hatte längst den Völkerverkehr als höchst rege erwiesen, aber die Ethnologie war keine Wissenschaft, nur Dilettanten beschäftigten sich mit ihr. Man muß die trefflicher, hier nicht wörtlich zitierten Ausführungen selbst nachlesen. S. 76 sagt er: „Nicht Entstehung auf allen Punkten der Erde, sondern Entlehnung, so heißt jetzt die Formel".

Lefmann sagt in seiner Geschichte Indiens 10, es sei ein historisches Gesetz, daß die großen Einflüsse der Kulturen erst spät ein- 
gesehen würden. Erst neuerdings sei z. B. erkannt worden, daß der Einfluß der Araber bis nach Canton und Sumatra gereicht habe. Man könnte dasselbe von den arabischen Einwirkungen auf das mittelalterliche Europa sagen, auf den Burdach neuerdings hinwies (Sitzungsber. Berl. Ak. Wiss. 1904, 900). Die Griechen wußten von einem historischen Gesichtspunkt bitter wenig. Es wäre interessant und äußerst lehrreich, einmal ihr Schrifttum daraufhin durchzugehen. Bei uns war die dognatische Handhabung der Wissenschaften unendlich lange in Bliite, später erfand man eine philosophische Grammatik, Philosophie der Sprache usw., bis schließlich der historische Gesichtspunkt gefunden wurde. Ähnlich war es in der Theologie bis auf die Tuibinger, im Recht bis auf Savigny usw.

Es ist leicht, eine kleine Auslese von Anzeichen der Beeinflussung und des Kulturzusammenhangs anzuführen. Um. erst einen Augenblick bei neueren Zeiten zn verweilen, in denen sich das handgreiflicher nachweisen läßt, wie kam es, daß im 18. Jahrhundert der Brite, der Italiener und ebenso der gute Deutsche sich mit Zopf und Perrücke kleideten? Das war gewiß ein Völkergedanke, eine generatio aequivoca in allen Staaten Europas. Oder war es Nachahmung Frankreichs? Doch beim Zopf blieb es nicht, auch nicht beim Alexandriner und drei Einheiten und dem Inhalt der gesamten Kunst, das ganze Denken und Philosophieren der Zeit war aufklärerisch, rationalistisch nach gleichem Geschmack. Und von unserer modernen Kunst, ob naturalistisch oder symbolistisch oder neuromantisch, beruht vieles wieder auf westlichen Vorbildern. . Die beginnende Erschließung Ostasiens machte sich in unserer Architektur und Malerei deutlich bemerkbar. Man subtrahiere doch einmal aus der Kultur irgend eines Landes der Erde alles, was an seiner Kultur nicht eigenes Gewächs, sondern Import ist, und es wird bei genauer Pruifung nicht viel übrig bleiben, ob man die Hilfsmittel des täglichen Gebrauchs oder des geistigen Lebens heranzieht. Wenn man bedenkt, daß die Kultur eigentlich von jeher auf dem Austausch, dem Vergleich, dem Wettbewerb, dem freien Spiel der Kräfte beruhte, so erscheint das ganz natürlich. Kultur bildete sich da aus, wo der Handel blühte, wo der Kaufmann die Waren seiner Heimat als Tauschartikel feilbot. Nicht das Binnenland, sondern dic Küsten, nicht die einsamen Höfe, sondern die Knotenpunkte der Karawanensiraßen, nicht das flache Land, sondern das Gewiihl der Städte waren es, wo aus dem Austausch der Produkte 
sich Industrie, Gewerbfleiß, Wohlhabenheit und Kultur einstellten. Aus der Inzucht der Abgeschlossenheit ergaben sich nur Blutarmut und Niedergang. Wie der Boden um so fruchtbarer wird, je nachdriicklicher man mit Pflug und Egge seine Schollen durcheinanderschïttelt, so auch mit den Völkern. Sparta, das sich isolierte, blieb immer die Provinzialstadt; Athen, die Zentrale des Weltverkehrs, blicb auch eine geistige Hauptstadt der Welt. Die Landstadt Rom, von Pfahlbürgern und respektvollen Philistern bewohnt, bedeutete der Welt zehnmal weniger, als jede beliebige Stadt Großgriechenlands; als es die Griechen bei sich aufnahm, trotz Catos Zorn, begann es caput mundi zu werden. Und Ähnliches gilt von anderen Staaten auch. Also gerade der Güteraustausch ist das Belebende, Fördernde, so daß man, wo starke Produktivität auftritt, auf vorgängigen starken Umsatz zu schließen haben wird. Das physiologische Analogon der Blutverdünnung durch Inzucht ist hier auch am Platz; also auf möglichste Promiskuität aller Güter auf stärksten Umsatz kommt es an; Inzuch $九$ hindert das Gedeihen, Zuchtwahl und Auslese schützen das Ganze vor üblen Folgen verwildernder Promiskuität. . Auf diese Formeln lassen sich alle gemeinsamen, staatartigen Gebilde bringen, von der niederen organischen Welt bis herauf zur modernen Nationalökonomie. Freilich was ist dem Philologen diese Hekuba? Nie hat er sich viel um die Dinge seiner „Welt" gekümmert. Für biologische und nationalökonomische Dinge war er niemals interessiert. Aber die Wissenschaft von Hellas, einem der gewaltigsten Kulturfaktoren der Menschengeschichte, geht doch nicht die Philologen allein an, Griechenland oder vielmehr Athen, die veilchenbekränzte, dämonische Stadt, hat für die ganze Menschheit gearbeitet, jeder von uns ist von Athen beschenkt worden und hat die Pflicht des Dankes, die er nicht anders abstatten kann, als durch hingebende Liebe und innigen Anteil an der Blüte der heiligen Polis. Sollte der Philologe da das Recht haben, die gesunkenen langen Mauern durch eine chinesische Mauer. des Banausentums zu ersetzen und die Dornenhecke einer rückständigen Methode um sie zu pflanzen? Das Phänomen Attika gehört mitten in den Strom der Biologie, von allen Seiten muß es beleuchtet, zu jeder Welterscheinung in Beziehung gesetzit werden. Mit tausend Fäden an Athen gebunden hat der Mensch die wissenschaftliche Pflicht, alle Pfade, die dorthin führen, zu erkunden und für immer gangbar zu erhalten. Alle Strahlen der Entwicklung schnitten sich 
im Hafen Atheris, alle Kulturpotenzen drängten sich in die Erechtheusstadt, um von dort gesteigert und erhöht in die Welt zurückzukehren und die hohe Botschaft von der großen Metropolis allen Landen zu melden. Und wir sollten das Recht haben, dieses gewaltige Netz von Beziehungen zu zerreißen? Alle Wissenschaften waren eimmal in Athen angesiedelt, jede soll den Weg nach Athen suchen und ihre historischen Beziehungen fuir die Magna mater erkunden, jede ihr Licht auf sie werfen, bis sie von allen Richtungen bestrahlt plastisch vor uns steht.

Und doch gab es auch vor. Athen Krystallisationspunkte der Kultur. Die Amarnabriefe zeigen, daß in einer viel früheren Zeit die Keilschriftsprache den Weltverkehr beherrschte. Die Pharaonen wie die Mitanikönige, die Herren von Assur und Babel, wie die Chetafürsten verstanden sie und wechselten ihre Briefe in diesen Zeichen, ja auf Kypros und Kreta (?) hat man Tontafeln mit diesen Ideogrammen gefunden. Wer will noch leugnen, daß ein Weltverkehr im 3. und 2. vorchristlichen Jahrtausend bestand? Die Wincklerschen Funde in Bogházköi haben die Zone dieser Kultur noch erweitert. Die großen Reste der Heerstraßen und sonstigen Verkehrsmittel zeigen, daß die Verbindungen der Völker schon in ältester erreichbarer Zeit ungemein ausgebildet waren. Dàs Buch von W. Max Müller, „Asien und Europa“, stellt eine Fülle von Beziehungen beider Erdteile dar. In prähistorischer Zeit schon war der Süden der gebende Teil. Die Mittelmeervölker z. B. lernten das Metall, wie E. Pernice in Lehnerts neuer "Geschichte des Kunstgewerbes“ I 47, bemerkt, friiher kennen als das nördliche Europa, und Vorderasien und das Niltal kannten Metallarbeit schon lange vor den Mittelmeerländern. Im Innern Afrikas besteht z. Z. noch die Steinzeit, da es eben am Austausch und Verkehr mangelt. Zur Zeit der zwölften Dynastie bestand zwischen Ägypten und der ägäischen Kultur ein reger Austausch (ib. 53) ${ }^{1}$ ). Die Steinschneidekunst hat sich nach Pernice (58) der sich übrigens durchaus nicht etwa als warmer Anhänger der Entlehnungstheorie zeigt, von Babylonien aus über Vorderasien bis zu den Griechen verbreitet. Die assyrischen Steine sind prunkvoll

1) In hellenistischer Zeit dagegen hat das alte Ägypten von der jüngeren Kultur der. Sieger so gut wie nichts angenommen. S. Wiedemann Mélanges Nicole 561. 
im Formenvortrag, bei den Hethitern waltet das Ornament vor, dire persischen Produkte sind kraftlos und nüchtern, aber ,alle zehren in den Darstellumgen von dem Erbe der babylonischen Kunst": (58). In der höchsten Stadt des Hïgels vom. Hissarlik ist ein starker Import kretisch-mykenischer Kunst bemerkbar, der eine einheimische Produktion zu lebhafter Konkurrenz anstachelte (65). In der Technik zeigt sich die mykenische Kunst von Babylon beeinflußt, wenn sie auch in der Art der Darstellung damn eigene Wege geht (73). Die Bereitung der Fayencen lernten die Kreter von den Ägyptern (81). Wie auch der friihattische Vasenstil dem Orient verpflichtet ist, stellt Pernice sehr plausibel dar (84). Auch die Bronzetechnik empfing von Osten her ihre Anregungen (109), ebenso wie die Goldschmiedekunst (118f.). Daß es auf anderen Gebieten nicht viel anders stand, ist ein naheliegender Schluß. Leider ist die Kunst des flüchtigen Worts und Klangs nicht in so vielen Überresten zu verfolgen wie die des Meißels oder Töpferrades sonst würde man auch hier Wunder erleben. Aber die Sprachen Kleinasiens sind leider großenteils untergegangen, teils aber in noch unentzifferten Alphabeten geschrieben. Tenn die Chetasprache, die Lykischen u. a. Inschriften einmal gedeutet sein werden, ist noch mancher Aufschluß zul erwarten.

Auch die indo-iranische Kultur schloß sich nicht gegen die Außenwelt ab, im zweiten Jahrtausend stand Indien schon im. Weltverkehr (O. Francke, ZDMG 1893, 595 ff.) Es hatte seine Beziehungen zu Bâveru, d. i. Babylon wohl nicht erst in der Zeit der Jatakam (ib. 606); wie denn auch seine Küstenschiffahrt später jedenfalls beträchtlich war (608). Auch ïber friihe Reisen indischer Kaufleute erfährt man einiges (K. E. Neumann, Reden Buddhos, II 548, Bühler, Grundriß I, II, 5). In astronomischer u. a. Beziehung hängen die Inder von Babylon ab, dem sie auch sonst verpflichtet sind (s. Eckstein in Webers Ind. Stud. II 369, der auch den altorientalischen Weltrerkehr betont). Ungekehrt zeigen die Darstellungen in Indien heimischer Tiere auf dem Obelisken von Niniveh (Lefm,ann, Ind. Gesch. 2) und die von Winckler in Chetareich entdeckten indischen Götternamen, daß die Kunde vom. Fünfstromland frühzeitig weit nach Westen gedrungen war. Im Mittelaltar wirkt Indien faszinierend auf den Okzident, nicht nur seines Reichtums wegen, und noch unsere vergleichende Sprachwissenschaft ist der indischen zu Dank verpflichtet (Schröder, Indiens Kultur u. Litt. 701). Aber sowie von Griechenland 
die Rede ist, heißt es immer, die Entfernungen seien viel zu groß, die Wege viel zu weit gewesen, als ob die Kultur nicht Meere durchschwommen und Wüsten und Felsenkämme überflogen hätte. Man bedenke nur, welche Länderstrecken die Fabel, die Novelle, der Schwank usw., Indiens durchwandert haben (vgl. Mailath Magyar. Sagen 279 u. G. Jacob, Östliche Kulturelemente im Abendland, 1912, eine sehr inhaltreiche Schrift):

Eine chinesische Weltkarte weist merkwürdige Übereinstimmung mit der von Peiser (Z. Ass. IV 360 ff.) veröffentlichten babylonischen Weltkarte auf (W. Schultz, Altjon. Mystik 149). Die Theorie von der chinesisch-babylonischen Verwandtschaft gewinnt neuerdings immer mehr Anhänger (s. Richthofen, China I $404 \mathrm{ff}$.); man wird natürlich an indische Vermittlung glauben, für die denn auch Anzeichen in reicher Fülle vorhanden sind. Die Sprache, die vertikale Schrift, die Mythologie u. a. weisen deutlich auf Vorderasien hin. Das wäre alles an sich gar nicht so merkwürdig; benachbarte Völker würden sich kulturell immer beeinflussen. Ganz etwas anderes ist es, weun zwischen zwei solchen Ländern ein Weltmeer wie der stille Ozean liegt. Es ist gelungen, sagt P. Ehrenreich (Zeitschr. f. Ethnol. 1908 Supplbd. S. 3), „,den engen Zusammenhang der nordasiatischen Mrthen mit der nordwestamerikanischen endgiiltig sicher zu stellen und so die ethnologische Kluft zwischen der alten und neuen Welt in einer wichtigen Beziehung zu überbriicken". S. 77 bringt er ,,asiatische Sagenelemente in Amerika" bei; man muß das bei ihm selbst nachlesen, um von der Richtigkeit dieser Theorie völlig überzeugt zu werden (vgl. auch 34). Die polynesischen Zwischenglieder weist Ratzel auf (Anthropogeogr. 576, 581, 583; vgl. auch Wuttke, Gesch. d. Heident. $§ 185$; Zöekler, Gesch. d. Askese I 86 Anm.). An eine amerikanische Urmenschheit, wird man bei dem Verhältnis des Menschen zu Platyrrinen und Katarrinen nicht denken, wohl aber an Übertragung aus Ostasien über das Inselreich des großen Ozeans. Auf Einzelnes müßte unten noch zurückgekommen werden.

Wenn aber die Kultur von Vorderasien in östlicher Richtung den gewaltigen Kontinent von Mittel- und Ostasien mit seinen ungeheuren natürlichen Hindernissen, Wüsten, Steppen, Gebirgsmauern u. a. überschritten hat, und sogar in letzten Ausläufern über den großen Ozean ging und Amerika streifte, wird man ihr wohl zutrauen diirfen, daß sie von Mesopotamien etwa durch Kleinasien nach 
(iriechenlinnd kann. Es wäre lächerlich, das bestreiten zu wollen. Man vergleiche nur einmal auf der Karte die beiden Wege. Die natürlichen Hindernisse sind hicr gar nicht größer als dort, vielmehr weit geringer. Außerdem gestattete die fiir jeden Austausch gleichsam prädestinierte Küstenformation der Levante und Ostgriechenlands eine vicl schnellere Übertragung als in Innerasien, dessen Wüsten noch jetzt unsägliche Terrainschwierigkeiten bereiten. Die Denkmäler Kleinasiens sprechen mit Beredtsamkeit vom östlichen Einfluß. Die öden Felsgräber Paphlagoniens, die Baureste.Phrygiens usw. bekunden es immer wieder. Die mykenisch-kretische Kunst hat bei aller Selbständigkeit orientalische Bestandteile, wie man ja auch Tontafeln auf Kreta gefunden hat (Athenäum 1900, 19. Mai, 634). Es ist iiber die archäologischen Zusammenhänge zwischen Hellas und Asien schon vieles geschrieben worden, meistens freilich noch wenig Abschließendes. Die Fragen sind im Einzelnen zudem. auch so im. Fluß und das Material noch so unvollständig, daß hier nur mit wenigen Worten darïber hingegangen werden soll. Das phrygische Felsengrab von Bojük-Arslantasch liegt mitten auf der Vorderseite eines würfelförmig zugehauenen Felsblocks. Rechts und links von dem Grabe erheben sich auf den Vorderpranken zwei mächtige Löwen, zwischen denen eine Säule aufragt. Man wird bei dem Anblick (s. E. Brandenburg, Phrygien, AO. IX 2, 10) durch die frappante Ähnlichkeit mit dem m.ykenischen Löwentor überrascht. Die ältere archäologische Schule, bemerkt Brandenburg S. 11 sehr richtig, konstatierte einfach griechischen Einfluß. Aber gerade für die mykenische Kultur ist doch asiatischer Einfluß sehr wahrscheinlich und außerdem „kann man unmöglich zugeben, daß von Griechenland herüber das schwächliche Vorbild der Löwen von Mykene dieser geradezu grandiosen Skulptur als Vorbild gedient haben soll. Diese matten Tiere von Mykenä machen den Eindruck von dressierten Zirkuslöwen, die sich in geschulter Pose auf einen Untersatz stellen müssen. Wie natürlich sind dagegen die Löwen von Bojuk Arslan Tasch - " (ib.). Er erkennt an verschiedenen stilkritischen Details, wie den stark abgerundeten Rändern der Darstellung hettitischen Einfluß. Vergleichbar ist auch das Tor von Sendschirli (s. Winckler, Forschgn. II 371, 2) mit den zwei ansteigenden Ziegen. Solcher Anhaltspunkte für asiatischen Kulturimport gibt es aber noch viele und gäbe es wahrscheinlich noch unendlich viel mehr, wenn der Spaten in Kleinasien 
fleißiger gervesen wäre, als bisher leider der Fall sein konnte. Besonders beredt ist ja die Gemmenkunst der Griechen, die nach Furtwängler (Antike Gemmen III, 1) ganz auf babylonischen Mustern beruht. Wichtig ist auch, was Oberhummer (Phöniz. in Akarnan. $17 \mathrm{ff}$.), Puchstein in der deutschen Orientgesellschaft u. a. mitgeteilt haben. Auch das Kuppelgrab bei Volo in Thessalien in der Nähe des alten Jolkos, das unter Cavvadias' Leitung vor einiger Zeit bloßgelegt wurde, weist auf den mykenischen Kreis und weiter auf dem Orient hin. Ein Eingehen auf die Vergleichung kretischer und orientalischer Grundrisse, Dekorationen und Bildwerke würde hier zu weit führen, es muß auf Evans' Berichte im Annual of the Brit .School und die Mitteilungen der archäologischen Institute verwiesen werden.

Die literarische Tradition ist ebenfalls beredt genug. Die Hellenen selbst wollten gar nicht die Schöpfer ihrer Kultur sein. Herodot hat sich ja deutlich darïber ausgesprochen (II, 4, 49 ff. 81,156 u. a.). Hippokrates redet von den Asiaten als von kulturell überlegenen Menschen (de aere 12). Keilinschriftliche Briefe wurden in Athen geöffnet und gelesen. Aristeides nimmt den Pharnabazos in Eion

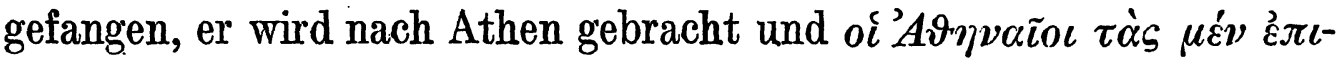

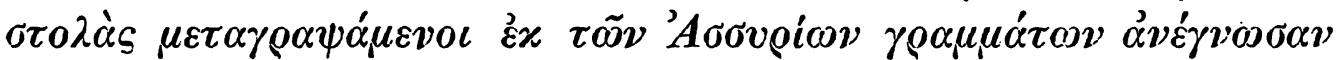
(Thuk. IV, 50, 2) und Thukydides gibt auch den Inhalt des Briefes an (s. Nöldeke, Hermes 5, 461). In Platons Timaios sagt der Ägypter

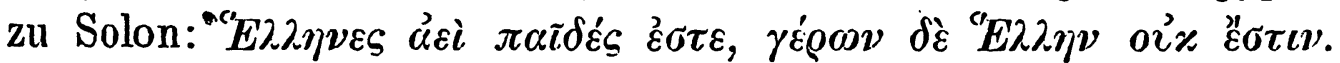

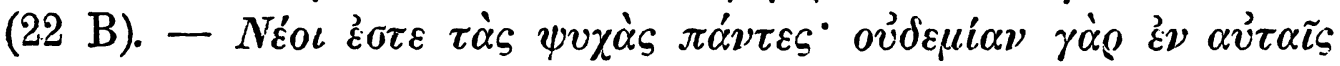

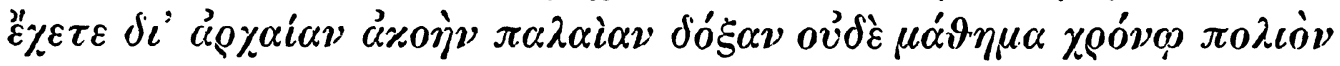
ớ $\delta \dot{v} v$, und etwas von einem tiefwurzelnden Respekt des Hellenen vor den alten Kulturen des Orients drückte sich darin aus, deren Einfluß auf das alte Hellas niemals verkannt wurde (cf. Herod. 6, 54; 7, 8).

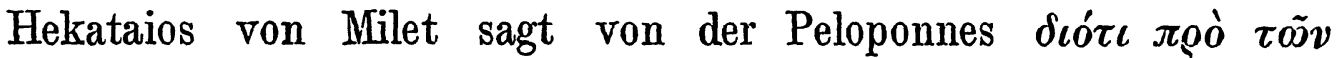

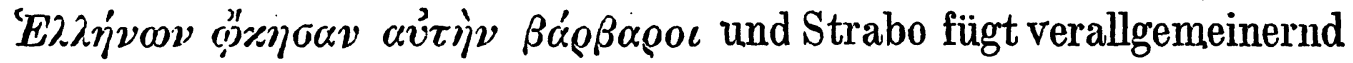

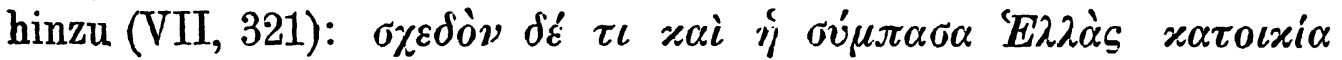

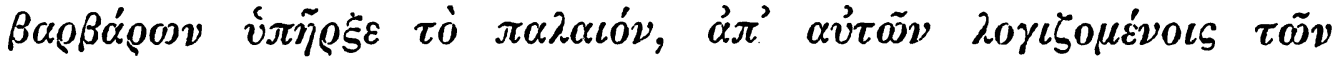

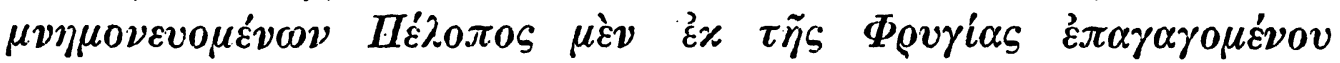

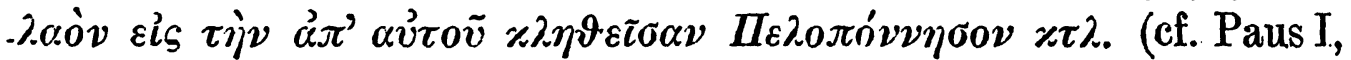
39,6). Die Griechen lasen die Schriften des Persers Osthanes leiden-

1) Plato Tim. 22: der Griechen altes Wissen. Billeter Zürich Progr. d. Kantonssch. 1901. 
schaftlich, ad rabiem, non aviditatem modo scientiae eius Graccorum populos egit (Plin. N. H. 30, 2, 5), es steht zwar schr schlimm um ihre Jehtheit (Jiels Vorsokr. 464), aber solche Notizen sind doch vielleicht symptomatisch fiir die ganze Richtung. Dic Athener liebten nämlich alles Ausländische. 'AHrvain $\delta^{2}$

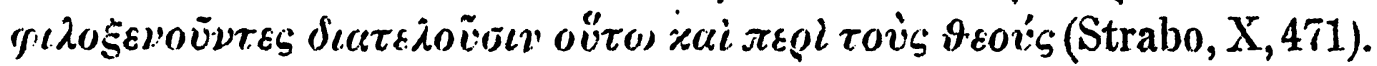
Ein besonderes Interesse heftete sich immer an die Frage, ob die griechische Philosophie auf orientalischem. Einfluß beruhe oder nicht. Hier ist natürlich nicht der Ort, das zu entscheiden. Zeller hat gegen Röth, Ritter, Gladisch u. a. die Beeinflussung bestritten, und seine Schüler folgen ihm darin. Aber die neuste Generation wird wieder ungetreu, und man kann es ihr nicht verdenken. Noch hat es keine Epoche in der Geschichte der Philosophie gegeben, die in ihrem Denken nicht von einer älteren abhängig gewesen wäre; sollte Griechenland hier wieder ganz allein stehen? Man ist durch unser Zeitalter der klassischen Humanität, durch Winckelmann, Goethe, Thorwaldsen daran gewöhnt, die Griechen als eine leuchtende, unvermittelte Episode in der Geschichte vorzustellen, was an sich begreiflich und schön ist; jetzt aber stehen wir im Zeitalter der Biologie und damit sind wir verpflichtet, jene Grundansicht und auch alle in ihrem Gefolge festgewurzelten Ansichten zu revidieren; zu diesen im Gefolge der Hauptlehre festgehaltenen Dogmen gehört die instinktive Überschätzung. hellenischer Produktivität auf philosophischem Gebiet. Das indische Denken ist erst seit viel kürzerer Zeit bei uns bekannt geworden und hat alsbald tief Wurzel geschlagen, Schopenhauer stand in seinem Bann, Richard Wagner und Nietzsche gleichfalls. Der Buddhismus ist eine Weltreligion gewesen und ist es noch, und seine Propaganda umfaßt die ganze Welt. Es gibt bei uns begeisterte Buddhisten. Bei uns hat er also ganze Systeme der Philosophie geschaffen, das ganze 19. Jahrhundert ist vielleicht ohne Berücksichtigung dieses Elements nicht ganz zu verstehen, da eben seine größten Denker den Strahlen dieses Lichts so lange ausgesetzt waren. Wenn nun in unserer erleuchteten Zeit die Kunde aus dem Morgenland so entscheidend wirkte, sollte die Macht jener orientalischen Gedanken auf viel primitivere Völker ,nicht entsprechend stärker gewirkt haben? Die Lehre des Buddha war ja ziemlich jung, aber die Weisheit der Upanischads strahlte wie Radium magisch-geheimnisvolle Strahlen aus, ohne je an der eigenen Konsistenz und Herrlichkeit Abbruch zu erleiden. 
Sollten die Lichtgedanken dieser Dichterphilosophie, an denen Schopenhauer sich für Lebenszeit berauschte, den empfänglichen Hellenen nichts gevresen sein? Das wäre ein geschichtlicher Nonsens! Und daß jene Gedanken nicht trotz aller Entfernungen und Grenzen durch alle Ritzen und Spalten drangen, wird uns niemand mehr einreden. Wir glauben jetzt an die Orientreisen der ältesten griechischen Philosophen, wir schließen aus dem dichten Rauch apokrypser Tradition auf wirkliches Feuer. Jetzt wissen wir auch im Einzelnen viel mehr als Röth und Gladisch wußten, z. B., daß der philosophische Dialog mindestens formell aus dem Osten stammt. Man versuche doch, das zu bestreiten und zu widerlegen! Die Griechen haben keine Religion geschaffen, die welterobernd Generationen und Völker an ihr Bekenntnis fesselte, wie der Orient es verschiedentlich tat. Das Hellenentum hat in religiösen Dingen mehr zersetzend als schaffend gewirkt, das hängt mit der Zeit seiner Volksblüte zusammen, drïckt daher keinen Mangel aus. Das Hellenentum setzte ein, als die orientalischen großen Hierarchien sich in einen Zustand des Zerfalls befanden und in der Heimat schon befehdet wurden, wie schon die Veden selbst stellenweise bezeugen. Wohl bestand in Hellas eine tiefe Mystik, aber der verstandesfrohe, dialektische, taghell blickende Grieche war für den gleichzeitigen Rationalismus empfänglicher. Sokrates hat keine Schwärmer herangebildet. Er selbst ist eine ganz realistische Gestalt ohne Heiligenschein und Himmelfahrt. Der dionysische Rausch, den Nietzsche aus der attischen Tragödie herausliest, war im 5. Jahrhundert und später jedenfalls unbekannt, es ist eine wenngleich schöne Phantasie des Philosophen, die wohl auch nicht streng historisch gemeint war. Die Schwärmer, die Griechenland heranbildete, Antistlienes, Diogenes usw., waren ironische Spötter, keine weltfremden Ideologen, wie die Asketen des Orients, von denen sie wohl beeinflußt sind. Und Plato mit all seiner Mythologie und pythagoreischen Spekulation verliert nie den Boden unter den Füßen. Aristoteles hat in der Jugend romantische Wallungen, Herakleides Pontikos, Euemeros und ähnliche Phantasten bauen Luftschlösser, aber keine Klosterhallen. Akademie, Lykeion und Kynosarges waren keine Büßerhaine. Ein Schatten romantischen Halbdunkels flimmert erst in hellenistischer Zeit aus den Dunst des alexandrinischen Völkergemischs und anderer asiatischer Hinterländer über das Griechenland hin, das nun schon kein reines Griechen- 
tum mehr ist, iiber das sich die Gewölke synkretistischer und abstruser Religionsgebilde hinwälzen. Den Neupythagoreern und Neuplatonikern fehlt schon der taghelle Rationalismus des klassischen Atheners von ehedem ganz und gar, finsterer Askese, inbrünstiger Sch wärmerei und Liturgik ist er durchaus nicht abgeneigt. Apollonios von Tyana und andere Wanderprediger finden gläubigen Anhang; Juden und Christen beherrschen bald die Welt, Plotin, Proklos, Porphyrios stehen ihnen schon so nahe, daß der Abstand kaum wahrnehmbar ist; und mit Julian stirbt, möchte man sagen, auf Jahrhunderte der letzte Verstandesmensch, wenn nicht. auch er längst von dem Weihrauch der Zeitstimmung tiefumnebelt gewesen wäre. Die Geister des Orients feiern einen vollständigen Sieg, den die Kirche in vollen Zügen genießt. Das Griechentum hat in dieser neuen Welt keinen Raum mehr und versinkt; erst als die Zauberformel des Bekenntnisses seine Macht einzubüßen droht und man auf die ersten geheimen Proteste des Verstandes trifft, entsinnt man sich des. vergessenen Heidentums, und aus arabischer Hand übernimmt man Aristoteles' Logik, um das gefährdete Dogma mit den aus diesem Arsenal geholten Verstandeswaffen zu verteidigen. Da entsann man sich der Griechen, zu seinem Rationalismus flüchtete sich die bedrängte Mystik.

Also Religionskeime wucherten in Attikas Boden nicht. Haben die Athener aber eine Weltphilosophie geschaffen? Hat eine der von ihnen gelehrten Weltanschauungen, ja ganzen Epochen, ganzen Völkerkomplexen ihren Stempel aufgedrückt? Die vorderasiatische Kosmologie und Naturphilosopie beherrscht die ganze Kulturwelt ihrer Zeit, wie Descartes und Leibniz ihr Jahrhundert beherrschten. Platons Schüler glaubten schon nicht mehr an den Meister, magis amica veritas. Eine Schule schloß sich an die andere an, keiner blieb der Sieg, nur Neuplatonismus und Gnosis haben ihre Zeit ganz erfüllt. Man kann das auch anders beurteilen. Aber die Griechen haben immer durch ihre Kultur geblendet, haben gelehrt und erzogen, aber sie haben keinen Fanatismus erzeugt, haben Sophisten und Sillographen gehabt, aber keinen Mohammed, keinen heulenden Derwisch, keinen heiligen Krieg, wenn man von den delphischen Katzbalgereien absieht, keine Märtyrer, keine Kirchenmusik erzeugt. Wohl hatten sie ihr Eleusis und Samothrake, ihre Kybelepriester und Tympanisten, aber sie nahmen das selbst nicht ernst; in der Tragödie 
unterliegen Pentheus und Lykurgos, in der Wirklichkeit schimpft das Volk wie Demosthenes auf das Hyes Attes der Agyrten. Gewiß hatten sie auch keine Inquisition und tausend andere Schattenseiten der Mystik. Aber ihnen fehlte doch schließlich auch der Schlüssel zum Heiligtum des Herzens. Letzte Worte des Menschentums hat Hellas selten gesprochen. Es schwebt in himmlischer Anmut über der Prosa des Alltags, aber Eros flattert nicht dưrch die sieben Planetenringe des gnostischen Firmaments zur höchsten Klarheit. Die letzten Worte spricht, die letzten Fragen stellt der Orient und mit seiner Weisheit speist er die Völker. Die tiefsten Empfindungen werden dort ausgelöst. Die Inbrust babylonischer Psalmen ist dem Griechen fremd. Das Heiligste, höchste Faßbare wird ihm nicht lebendig, insofern ist er ewig Heide. Die letzten Geheimnisse der gequälten Menschenbrust erschließen sich ihm nicht, wie er die letzten mystischen Rätsel man möchte sagen dilettantisch betastet, aber nicht aufbricht: Die Geheimlehren des Orients gipfeln in der Alleinheit des höchsten Wesens, Xenophanes und andere greifen wohl nach dieser Höhe, ermessen sie aber nicht mit dem Gefühl. Der Grieche hat das Welträtsel gelöst, nach dem Jahrhundert verschieden, aber immer mit Bestimmtheit; der Orientale hat über all seiner Weisheit stets die höhere Allmacht, der gegenüber nur das Eingeständnis der Ohnmacht am Platz sein kann. Die Selbsterkenntnis des Sokrates ist bei ihm demütiges Reizen vor der geahnten Urkraft. Die Griechen hatten keinen besonderen Priesterstand, aber sie hatten auch keinen Glauben. Den Geschmack werden sie stets beherrschen, die Kunst, die Wissenschaft u. a. wird 'ihnen stets Dank zollen, die Menschheit wird nicht $\mathrm{zu}$ ihnen wallfahrten, die letzten Wege fuihren nicht nach Athen. Ein griechisches Weltreich gab es nie, auch die Geister werden ihrem Bann niemals ganz verfallen: Die letzten Fragen werden an sie nicht gestellt. So mußten sie dem orientalischen, Jahrtausende älteren, mächtigen Einfluß auf allen Gebieten erliegen, und wer das bestreitet, gerät mit historischer Logik und Folgerichtigkeit in unlöslichen Konflikt.

Es seien noch einige Bemerkungen dazu in freier Folge gestattet. Die Abhängigkeit von Babylon in astronomischen Dingen bezeugt

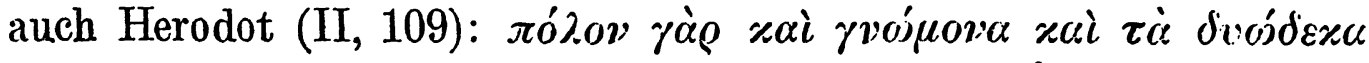

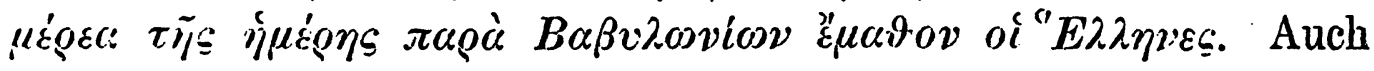


die Steingewichte der Jitmusk(rs beruhen auf dieser Quelle ${ }^{1}$ ). Auch der bahylonische Einfluß auf Indien wird jetzt mehr anerkannt2), mau braucht nur die \%. T. wörtlich iibereinstimmenden Beschwörungsformeln \%u beachten ${ }^{3}$ ), un sich davon zu überzeugen.

Als Bindeglied sind die ('hattu aufzufassen. In der zweiten Stadt 'Troja fanden sich Spinnwirteln mit hettitischen Schriftzeichen, und tïnerne Siegelzylinder. Auch auf Kypros sind hettistische Zylinder keine Seltenheit. ${ }^{4}$ )

Auch Indiens Selbständigkeit Hellas gegenuiber tritt deutlicher hervor, seit man über die Primordien des indischen Schauspiels z. B. anders denkt als vor einigen Jahrzehnten. Pischel z. B. urteilt in seiner Abhandlung über das indische Schattentheater, durch dieses sei die letztc Liicke in der Entwicklung des indischen Dramas ausgefüllt. Indien habe keinen starken, nachhaltigen Einfluß von Griechenland empfangen; Menander-Milinda wird Buddhist, Alexander hinterläßt im Pendshab keine nachhaltigen Wirkungen. Die Annahme, der griechische Mimus habe den Orient beeinflußt, sei rundweg zu verneinen; die Entlehnenden seien vielmehr die Griechen gewesen ${ }^{5}$ ). Für das Umsichgreifen des Verkehrs sprechen auch die von Winckler in Boghaz-köi gefundenen Tafeln mit den Namen Indra Mitra Varuna. .

Kleinasien gilt dem Hellenen als Heimat höherer Kultur. Einem Feingebildeten ruft Alkman zu: Du bist nicht ein Bauer, nicht ein

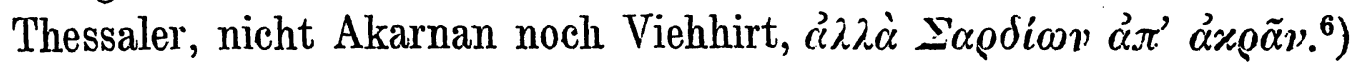

Sophokles verwendet in der Antigone ein altorientalisches Motiv, das er bei Herodot fand. Fast möchte man fragen, ob das Verbot des Kreon, den Leichnam zu bestatten, nicht schließlich auch auf östlichem Einfluß, auf der iranischen Sitte der Totenaussetzung beruht, die denn auch, z. B. in der Sassanidenzeit unter Ardeschir I zu be-

1) Graffunder Hermes 1908, 450. cf. Ideler, Böckh, Lefmann u. v. Eckstein Ind. Stud. II 369, der sehr verständig zu der Frage Stellung nimmt und die Griechen nicht aus dem. großen Weltzusammenhang nehmen möchte.

2) Hirt Indogermanen II 487.

3) AO VII, 4, 17.

4) Speck Handelsgesch. d. Altert. I 242.

5) Sitzungsber. Berl. Ak. 1906, 501 f. - Vgl. ferner Kern-Jacobi.

G. d. Buddhism. 306, 6. Marquart Osteurop.-ostasiat. Streifzüge.

$\left.{ }^{6}\right)$ Alkman fr. 24 . cf. Diels Hermes 31, 364. 
sonderen Verboten der Bestattung führte. Spuren der Sitte bietet ja der Anfang des Buches Tobit.

In Griechenland waren in der zweiten Hälfte des fünften Jahrhunderts persische Waren sehr modern und beherrschten den Markt. Die Phoiniker, die ja in Attika selbst dem Namen nach fortdauerten (Töpffer, Att. Geneal. 300), Ägypter usw. steuerten dazu bei, aus Kypros kam Getreide, Karthago, Sardes und der fernere Osten standen nicht zuriick $^{1}$ ). Sogar die Mode weist nach Osten, wie ein Vergleich zwischen babylonischen und mykenischen Volantröcken lehrt²), die Beziehungen waren eben jederzeit rege ${ }^{3}$ ). Der Grieche spricht immer gern vom Orient, der Orientale von Javana doch nur sehr selten.

Beachtenswert sind auch Furtwänglers Worte: Es gilt für die Glyptik in Griechenland in ungleich höherem Maße als für andere Kunstzweige, daß die Anfänge nur im Zusammenhange mit der älteren Kunst des Orients recht zu begreifen und zu würdigen sind. Denn die Glyptik, das Schneiden von Bildern in harten edlen Steinen ist nicht wie bei den Völkern so allgemeine, gleichsam selbstverständliche Kunst wie das Ritzen und Bemalen des. Thons usw. - Sie scheint, genauer besehen, überhaupt nur eine einzige ursprüngliche Heimat zu haben, auf welche sich alle anderen Fälle ihres Auftretens mehr oder weniger zurïckführen lassen, das ist - Babylonien. Die ältesten Denkmäler der. Glyptik in Ägypten setzen doch bereits noch ältere in Babylonien voraus und sind einer der wichtigsten Beweise dafür, daß die Ägypter ron Osten her in Besitz gewisser mit den babylonischen übereinstimmender Kulturelemente in das Niltal eingewandert sind. - Die ältesten ägyptischen Gemmen sind Tonabdrücke von Siegeln, die dieselbe Zylinderform hatten, die in Babylon alle Zeit herrschend blieb $^{4}$ ) und für die Kleinkunst wird man keine Sondergesetze supponieren wollen, was hier galt, stand auch dort in Kraft, mag der National-

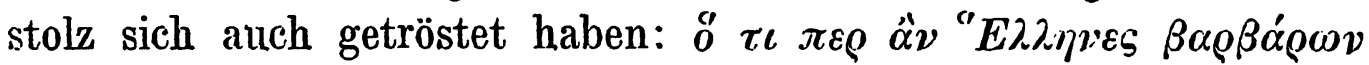

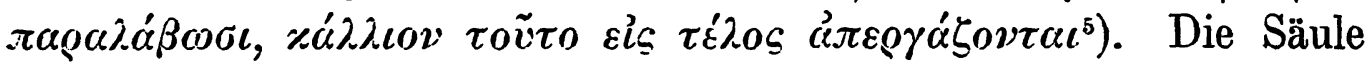

1) Wilamowitz Kydathen 76 f. cf. Oberhummer, Akarnanien. Strzygowski Kleinasien 178.

2) Jeremias $\mathrm{ATAO}^{2} 125$ u.a.

3) Vgl. auch Niebuhr MVAG 1899, $173 \mathrm{f}$., der wichtige historische Zusammenhänge scharfsinnig aufgedeckt hat.

$\left.{ }^{4}\right)$ Antike Gemmen III, 1.

5) Ps.-Plato Epinomis 987 E. 
ragte in Osi und West als Wahrzeichen empor, daß auch die große Kunst von Jänderschranken nicht gehemmt wird, wie aurh Puchstein \%. B. die jonische Säulen als klassisches Bauglied orientalischer Herkunft anerkennt ${ }^{1}$ ). Es wird so oft mit aller Bestimmtheit abgeurteilt, ob. eine wechselseitige Beeinflussung zwischen zwei Völkern möglich sei oder nicht, wïhrend man a priori dariiber doch eigentlich nicht entscheiden kann. Auch hier gilt es vorerst die Tatsachen selbst reden zu lassen 'und danach gleichsám ein System oder eine Psychologie des Weltverkehrs aufzubauen, auf der man dann ein für allemal fußen kann. Das alte Gerede von den weiten Entfernungen: 'die die Kultur nicht durchschreiten könne ${ }^{2}$ ) sollte doch nachgerade verstummen. Die vielen Sagen von Orientfahrten griechischer Philosophen, von Hellasfahrten asiatischer Weisen wie Osthanes $u$. a. mögen auf unglaubwürdiger Tradition beruhen, ein realer Kern liegt alledem immerhin zugrunde. Wie Dionysos ${ }^{3}$ ) zog die Kultur durch die Welt, und. auch Hellas war auf ihrem Triumphzug eine Station, an der sie freilich besonders gern und lang verweilte.

Es ist ein Hauptfehler, der immer wieder auftaucht, daß man gewisse Dinge als einmal gegeben hinnimmt, statt die Frage nach ihrem Ursprung zu stellen. So gilt es als Tatsache, daß die Griechen. die Philosophie geschaffen haben. Worauf die Philosophie überhaupt beruhe, was ihre Uranfänge seien, ob sie auf dem .Wege der Ent-wicklung aus einem anderen geistigen Element sich herausgebildet habe, wird nicht gefragt. Und doch ist dem so; doch beruht sie auf der Religion und dem Ritual, wie sich im Einzelnen erweisen ließe, und schon im Veda finden sich ihre Spuren ${ }^{4}$. Man hat denn auch die Anfänge der griechischen Philosophie vom östlichen Einfluß zu trennen. gesucht, und Eduard Zeller war einer der lautesten Rufer im Streit. Indessen hat neuerdings eine rückläufige Bewegung sich angekündigt, die Orientalistik fördert immer neue Dokumente für den gegenteiligen. Sachverhalt zutage. Die Jonier, Pythagoras usw. stehen dem Osten. nahe, selbst Platon lernt von der Gesprächsform der Inder und die

1) Brandenburg, OLZ 1909, 105 ff., der sehr verständig urteilt. MonteliusOrient. u. Europa. Strzygowski N. Jahrbücher 1909, 370 u. a.

2) z. B. Geffken Hermes 1906, 223.

3) cf. Gruppe Gr. Myth. 1516.

$\left.{ }^{4}\right)$ Winternitz Ind. Litt. I 197. Deußen, Allg. Gesch. d. Phil. I, 68. 
Stoa setzt ein mit einer Reihe von geborenen Orientalen und $-\varepsilon i, u i\rangle$

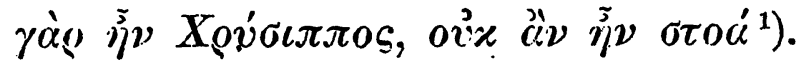

Auch die Musik der Griechen mit ihrer mathematisch-astralen Unterlage weist nach Osten ${ }^{2}$ ), wie denn ein Volk nicht leicht in einer oder einigen Beziehungen vom Ausland beeinflußt wird, in anderen nicht; der Einfluß ist gewöhnlich total oder gar nicht vorhanden, daß das Mutterland architektonisch von Kreta beeinflußt wurde, weiß $\left.\operatorname{man}^{3}\right)$, daß es dem Einfluß kretischer Gesamtkultur unterlag, wird man ohne weiteres schließen. Handelt es sich doch um unstetes Wandern der höchsten geistigen Güter, wie der Mexikaner von der großen Wanderschaft seiner Vorfahren von Norden her phantasiert,

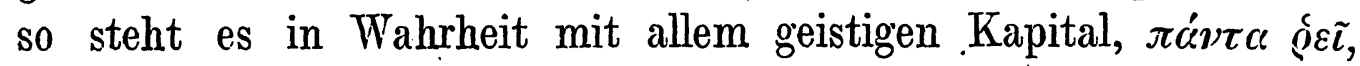
keine politischen, keine natürlichen Schranken tun hier Einhalt, unaufhaltsam geht es über die Grenzen und zerteilt sich quellend in alle Windrichtungen.

Verweilen wir zum Schluß noch ein wenig bei der vergleichenden Mythologie. Sie stand eine Zeitlang in üblem Ruf, man sagte ihr Phantasterei und Willkür nach. Der Hauptmangel wurde nicht betont; er war auch in äußeren Umständen begründet. Damals verglich man nämlich allein die Mythen der indogermanischen Völker unter einander, in falscher Anwendung der sprachvergleichenden Methode. Der Orient und die Symbolsprache der Naturvölker sind inzwischen unendlich mehr erschlossen worden, und man arbeitet jetzt mit ganz anderem Material. Dann aber ist jetzt ein Gesichtspunkt geltend geworden, der dies Material von einem Zentrum aus überblicken läßt. Schon Athanasius Kircher u. a. hatten in den Mythen siderische Vorgänge erblickt. Dann hatte besonders der zu wenig anerkannte Nork in einer Reihe von großen Werken die Göttersagen in Gestirnmythen aufgelöst, ganz neu aufgearbeitet und zu einem bündigen System aber verband den Astralglauben erst Hugo Winckler in seinen "Altorientalischen Forschungen“, seiner „Geschichte Israels" u. a. Sein System hier zu entwickeln, ist nicht notwendig. Es ist in seinen

1) Vgl. darüber Diels Elementum 41. Knaack, Berl. phil. Wochenschr. 1904, 1418, u. a. Auch Dalman Buddha 188 ff. u. a. ist zu vergleichen.

2) Athen, 175d u. a. leitung.

3) Seler Abhandlungen II 4f. W. Max Müller, Asien u. Europa, Ein- 
Sichriften niedergelegt und snine Anhänger bauen auf seinem Grunde fort. Groß sind auch die Verdienste Eduard Stuckens, der in vielen Ideen bereits voranging, und der Gebrüder Jeremias, die unermüdlich auf diesem Gebiet schaffen, und vieler anderer. Es wird damit ein system, eine Formel gegeben, die alle Mythologie wie cin Rätsel löst und alle in cinem sinn einigt. Darnach sind Sonne und Mond die eigentlichen Helden aller Göttersagen. $\mathrm{Daß}$ anderes daneben in Geltung bleibt, wird nicht bestritten, aber der Kern der Sache scheint damit getroffen zu sein. Näheres findet man in Alfred Jeremias' Werk „Das alte Testament im Licht des alten Orients“ (Leipzig 1907, 2. Aufl.). Das Zentrum dieser Mythologie war Babylon, wenn Winckler anch die Wanderhypothese nicht betont. Aus Babylon kamen die astronomischen Kenntnisse, die Münzen und Gewichte, wie Böckh nachwies, und nun auch die Mythen. Das war ein gewaltiger Fortschritt, und Winckler, dem der Ruhm dieser Funde zukommt, hat die mythologische Wissenschaft auf ein ganz neues Fundament gestellt. Die klassische Philologie hält sich fernab von der ,Pest der Deutungen: (Dieterich, Archiv f. Religionswiss. 1905, 490) und verharrt in dumpfer Riickständigkeit. Und doch waren die Griechen selbst hier minder unzugänglich und weitblickender als ihre ängstlichen Grenzhüter in unserer Zeit. Allegorische Deutung war ihnen seit Theagenes von Rhegion nicht fremd; so z. B. identifizierte Theagenes wohl den Helios und Hephaistos, Poseidon und Skamandros mit dem Wasser, Antonius mit dem Mond, Hera mit der Luft usw. (Schol. B zu 467). Auch Metrodor von Lampsakos, dessen Platon im Ion gedenkt, sah in Agamemnon den Äther, in Achilleus die Sonne, in Helena die Erde, in Paris die Luft, in Hektor den Mond u. a. Auch die Stoiker befolgten diese Methode (Diels, Doxogr. $90 \mathrm{ff}$.), die übrigens bei den Indern vorbereitet war. Auch bei Neueren gab es Anhänger der Richtung, wie z. B. Forchhammer. Im Einzelnen ist es leicht, sie zu bestreiten, schwerer dürfte der Nachweis fallen, daß ihr. Verfahren an sich ein falsches und fruchtloses ist. Die neuste Phase der Mythologie macht es im Gegenteil wahrscheinlich, daß ein berechtigter Kern all diesen Vermutungen zugrunde lag, nur daß aus Unkenntnis des Materials und mangelndem Überblick vielfach übers Ziel geschossen oder ins Blaue hinein konjiziert wurde.

Als klassischer Patron unserer Stellungnahme sei noch Sokrates

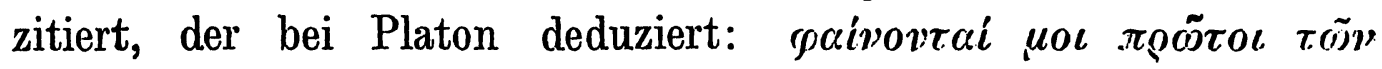




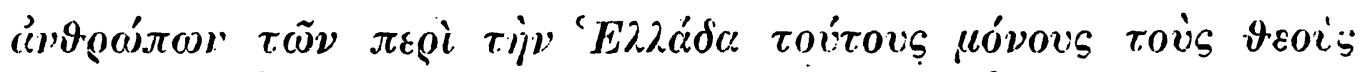

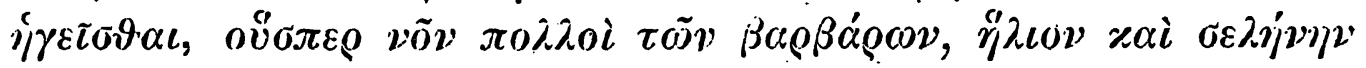

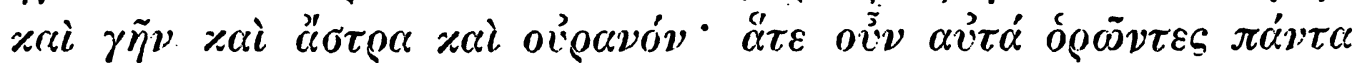

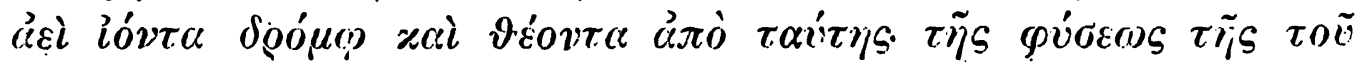

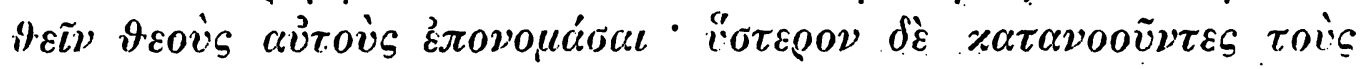

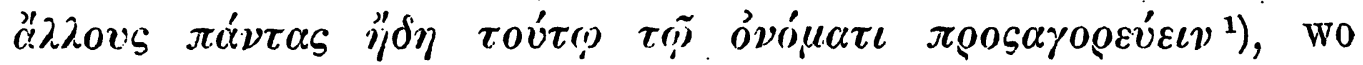
freilich die Etymologie belächelt wird; aber der astrale Grundgedanke besteht zurecht. Sonstige Richtungen seien gern als auchberechtigt zugegeben, auch die Mutter Erde Dieterichs, auch Regenzauber und Korndämonen haben ihre gewisse Daseinsberechtigung; im Übrigen ist unser Standpunkt fest verschanzt. Übrigens hat Usener schon ganz fortgeschrittenen. Ansichten gehuldigt und verdient auch hier mit Ehren genannt zu werden.

Noch einige Worte über Homer seien gestattet, der gegenwärtig die Geister wieder lebhaft beschäftigt, wie er das zu verschiedenen, nicht zu allen Zeiten der Geschichte getan. Was uns bei dem Namen Homer als geistige Persönlichkeit vorschwebt, gehört zu den Weltdichtern, wie Firdusi, Dante, Shakespeare usw., nicht zu den umfassenden Geistern wie Platon, Aristoteles usw. Er schildert keine komplizierten Kulturen und keine komplizierten Charaktere, er spricht die letzten Worte menschlicher Leidenschaft nicht aus, wie es Shakespeare und Goethe tun, er läßt sich nicht von einer Welle politischer Tendenzen emportragen, wie Jesajas, Archilochos, Savonarola, Rousseau, noch sammelt er die Narrheiten seiner Zeit im Hohlspiegel der Satire. Dennoch übțe er die grenzenlosen Wirkungen aus.

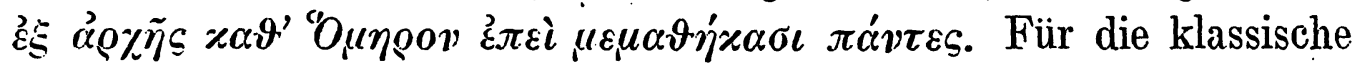
Zeit hat Tolkiehn das durchgeführt. Die Griechen und Römer ehrten jenen bis zuletzt. Im Mittelalter verschwand er. Die Renaissance wußte nichts mit ihm anzufangen. Vergil stand über ihm, wenn auch nicht so hoch wie Seneca zuerst über Euripides. Die Päpste setzten Preise für den Homerus Latimus aus, der lateinische I. H. Voss. blieb aus. Allmählich fand man sich in ihn hinein. Herder und Wolf stellten ihn in neuem Rahmen dar. Die Wissenschaft hatte sich seiner längst bemächtigt, aber die Alexandriner hafteten am Einzelnen, die Neueren fragten nach der dichterischen Persönlichkeit. Der adelige Sänger ward von der literarischen Volkspartei gegen die Hofdichtung ins

1) Cratyl. $397 \mathrm{CD}$. 
Feld grefilhrt, weil man ihn historisch noch unzurrichend begriff. Sio hatte er seinen wohlgemessenen Anteil an der Völkerbefreiung, Holden und Schlagworte konnte cr ja nicht bieten, sondern nur seinen sitil, der aber mächtig wirkte. Mit dem Sinken der Weltberregung crlahmte das Intcresse an Homer, und wie Großes auch im 19. Jahrhundert in der homerischen Frage geleistet wurde, man blieb schlieblich doch Epigon F. A. Wolfs, und aller Hader war wenig fruchtbarer Diadochenkrieg. Inzwischen drang immer ungestümer das historische Prinzip durch, das den beiden Epen gegenüber freilich einigermaßen

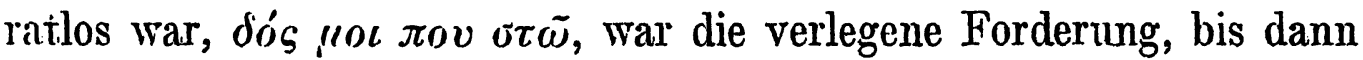
endlich der Anstoß von außen kam. Der Spaten enthüllte ganz neue Welten, und als das historische Prinzip nun wieder anpochte, ward ihm aufgetan, die neue homerische Frage regte sich, die Frage nach der geschichtlichen Einreihung und Authontie. Reichel, Robert, Andrew, Lang u. a. untersuchten die Beziehungen zw bloßgelegten Technik. Rohde forschte nach der Religion, doch blieben diese im Griechentum stecken. Der Spaten aber lehrte den großen Zusammenhang mit den Ländern jenseits des Bosporos und Hellespont. Wilamowitz erkannte: ,Die homerische Forschung kann sich hinfort nicht einmal mehr in den Grenzen des Griechischen halten". (Berl: Sitzungsber. 1906, 60). Auch die neue homerische Frage ist von grundlegender Bedeutung, es handelt sich um die Niederlegung eines Dogmas, der Lehre vom autochthonen Heldengesang in Hellas. Irrlehren zu beseitigen ist erspließlich in jedem, so auch in diesem. Fall. Daher war es ein großes Verdienst, daß P. Jensen von seinem orientalischen Bollwerk aus die Frage mutig erfaßte und Homer an die neugefundene Epik Babylons anschloß. Bei verkündigenden Thesen ist es einstweilen geblieben, man findet sie in der Zeitschrift für Assyriologie. Der zweite Band seines Werkes „Das Gilgamessepos in der Weltliteratur" soll ' das näher begründen. -

Die Gegner derartiger vergleichender Studien pflegen es als einen Trumpf auszuspielen: wenn man bei solchen Parallelen näher zusehe, finde man kaum Ähnlichkeit mehr, und die Analogie lasse sich nie bis ins Einzelne verfolgen. Auf diese Weise könnte man aber alle und jede Analogie aus der Welt schaffen, indem man eben statt der Ähnlichkeit Kongruenz und Identität verlangt: Die findet sich freilich nirgends, deshalb aber alle Ähnlichkeiten leugnen zu wollen, wäre armseliger Nonsens. Bei der Gelegenheit kann ich es mir 
doch nicht versagen, einem Rezensenten moines Buches ,Das philosophische Gespräch von Hiob bis Platon" hier noch einmal zu antworten. C. Ritter schrieb: (Berl. phil. Wochenschr. 1906, 1330) u. a.: "W'elch ärmliche Vorstellung von dem Menschen und von Gott, der ihn geschaffen hat, liegt allen diesen Betrachtungen und Schlüssen des Verf. zugrunde! - Wie unwahr, niedrig und phantastisch zugleich ist seine Psychologie. Wo irgend etwas Ähnliches in der Kulturgeschichte hervorgetreten ist, muß Abhängigkeit des einen vom andern angenommen werden." Es gehörte nicht viel dazu, den Gelehrten zu widerleg'en, was ihn dann zu einer gereizten Duplik in derselben Zeitschrift veranlaßte. Da bekam ich die ,unwahre, niedrige und phantastische Psychologie" zum zweitenmal zu hören. Er glaubte mich damit offenbar besonders schwer zu treffen. Nun, er hat Recht, ich bin gewiß kein Psychologe, aber ich wüßte auch nicht, daß ich mir das jemals eingebildet hätte, ja, daß ich auf diesem Gebiet überhaupt je einen Ehrgeiz besessen hätte. Ich erkenne auf diesem, wie auf unendlich vielen anderen Gebieten meine völlige Nullität unumwunden an. Aber nun fährt er fort, den Satz (S. 1 des Buches) „durch die Geschichte der Menschheit geht nur eine Kultur" vom Piedestal seiner Psychologie herab zu kommentieren: „Die Persönlichkeit rerliert dabei alle Bedeutung; der schöpferische Genius wird als bloße Summe in einem Kreuzungspunkt zusammentreffender Wellenberge der Kulturschwingungen aufgefaßt." Sehr schön, nur vergißt der Rezensent eins, daß die Kulturübertragung eben durch die großen Persönlichkeiten vollzogen wird. Um bei kontrollierbareren Gebieten zu bleiben; was hat Gottsched, den manche jetzt nur den Großen nannten, denn geleistet, das nicht auf Kulturübertragung hinausliefe. Winckelmann hat uns hellenische Schönheit, Lessing, Bürger und Goethe britische Kunstfreiheit vermittelt. Wo immer fruchtbare und folgenreiche Kulturmischungen stattgefunden haben, waren es große Persönlichkeiten, die die wichtige Arbeit verrichteten. Über die Frage, ob Männer die Geschichte machen oder nicht, wird Rezensent nicht so eilig aburteilen, auf den Standpunkt mittelalterlicher Welt' chroniken oder moderner Bilderbücher für artige Kinder wird er uns nicht zurückschrauben wollen, sondern vorher recht reiflich Taines u. a. Lehren in Erwägung ziehen. Wie aber soll der Ansicht von allmählicher Kulturwanderung eine ,ärmliche Vorstellung von dem Menschen und von Gott, der ihn geschaffen hat", zugrunde liegen? 
J)er Rezensent moint, die Kultur entstehe überall, wo sie erscheint, durch ein neues Wunder, durch göttliche (Offenbarung von Neuem. (iewiß ist sie iiberall göttlicher Offenbarung und uns ein unfaßbares Wunder, aber nicht mehr als jeder Käfer, jedes Blatt, jeder Kiesel. Dennoch ist die deutsche Anakreontik, die deutsche Alexandrinertragödie nicht etwa durch Urzengung oder eine himmlische Offenbarung, sondern durch Gottsched den Groben und seine löbliche Ehehälfte l,conore Adelgunde, geborene Kulmus nach Deutschland gekommen. Und so in zahllosen anderen Fällen. Aber es will denn doch scheinen, daß die Annahme eines Kulturmittelpunkts, von dem aus das Licht sich radial verbreitet habe, eine durchaus monotheistische Ansicht sei. Von einem Punkt geht das Licht der Welt aus. Ein Schöpfer regiert das Ganze, von einem Zentrum strahlen seine Wirkungen aus. Das scheint doch ein nichts weniger als heidnischer Standpunkt. Was will also Herr Ritter, wo bleibt seine Psychologie; er scheint ein ebenso armseliger Psychologe zu sein, wie ich. Meine Psychologie taugt nichts, aber die seinige ist auch nicht viel besser, wir sind darin beide Sünder und haben uns nichts vorzuwerfen. Im allgemeinen muß man der jetzigen Philologie eine gewisse Kurzsichtigkeit zum Yorwurf machen; die einzelnen Punkte werden erschöpfend behandelt, aber man verliert sich im Kleinkram, die großen Gesichtspunkte fehlen. Es fehlt aber auch der wissenschaftliche Eros, wie könnten sonst z. B. diejenigen, die in der bevorzugten Lage sind, das Material an sprack:lichen Kenntnissen zu besitzen, z. B. der wichtigen Frage nach den Einwirkungen des indischen Epos auf Arabien und den Okzident gegenüber kalt und ruhig bleiben? Man verschanzt sich in seinem. Gebiet, und in dem festen Bewußtsein, jeden dilettantischen Übergriff auf Nachbargebiete gemieden zu haben, treibt man den wichtigsten Fragen gegenüber Straußpolitik. $\tau \dot{\imath} \mu \iota \iota \mu \varepsilon^{\prime} \lambda \varepsilon \iota \tau \dot{\alpha}$. $\boldsymbol{c}^{\prime} \gamma \varepsilon \omega-$. Da steht es um. Wincklers Methode doch anders. Mag er hier und da, mag er oft, noch so oft geirrt haben: er hat aber durch den Wagemut, mit dem er eben viele Kulturgebiete übersah und durchforschte, gewaltige Entdeckungen gemacht. Er war es doch, der die Regierungszeit der 7 römischen Könige als eine astronomische Zahl nachwies. Durch dieselbe Methode umfassender Vergleichung gelang ihm ein anderer ebenso gewaltiger Fund; daß nämlich der ptolemäische Kanon durch Nabonassars Kalenderreform bestinmt sei (Winckler, Keilinschr. Bibl. II 274, 290, Ex Or. Lux II 2, 63 A. Jeremias $A T T^{2} \mathbf{A O}^{2} 68 \mathrm{f}$.). 
Diese und ähnliche Entdeckungen gelingen dem, der immer in seinen vier Pfählen bleibt, nicht, er hat sich dafür freilich auch von niemandem. jemals eine wissenschaftliche Tollkühnheit vorwerfen lassen, sondern ist immer hübsch sittsam. seine kleine Bahn gegangen. Ohne Tollkühnheit und Wagemut aber geht es nun einmal nicht in der Wissenschaft; das Vermeiden von Fehltritten ist aller Ehren wert, wer aber fördern und treiben will, muß ein wenig Abenteuerlust mitbringen, und gelegentlich vor einem tollen Streich nicht zurückschrecken. Die Myopie war aber von jeher ein Übelstand, der den wissenschaftlichen

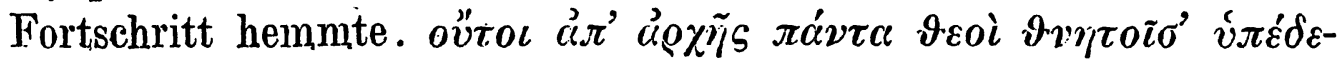

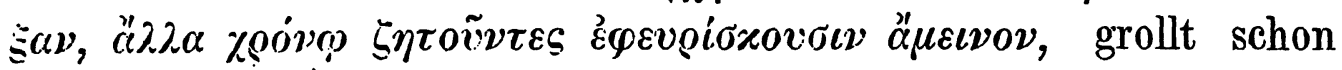
Xenophanes, und immer noch stehen sie sich oft feindlich gegenüber

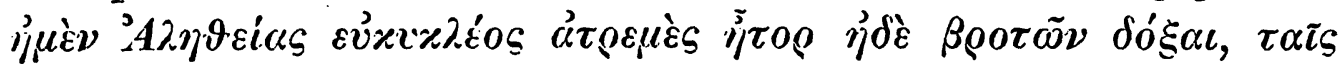

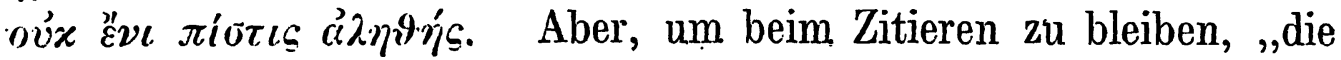
Wahrheit ist größer und mächtiger, als alles, die ganze Erde ruft nach der Wahrheit, der Himmel preist sie" (3 Esra 4,33),

Man darf es, um zum Ausgangspunkt zurückzukehren, wohl aussprechen, daß jede Geschichtsbetrachtung nur eine naturwissenschaftliche sei und umgekehrt. So groß angelegt, um noch einmal abzuschweifen, Goethes Aufsatz über die Natur auch ist, er läßt ein wenig das Hineinbeziehen des historischen Gebiets vermissen, das eine nicht minder reiche Ausbeute naturbetrachtender Ideen hergegeben hätte als das Naturreich im engeren Sinn. Aber es ist dem. homo sapiens nun einmal eigen, überall für die trennenden Grenzscheiden mehr Verständnis zu haben als für die verbindenden Gemeinsamkeiten, und so wird noch mancher auch mit weniger unzulänglichen Mitteln unternommene Versuch unser Problem $\mathfrak{z u}$ lösen, wirkungslos verlaufen. Ein anspruchsloser Ansatz wie dieser, wird keine Beachtung finden, aber die Idee kann nicht ruhen, sie ist triebkräftig und drängt zum Licht, und wenn sie einmal wieder von jemandem hervorgezogen wird, dann froelich urstaend! 